\section{Imagery in a short-term memory task}

\author{
SHEILA JONES \\ University College London, London, England
}

Instructions for two short-term memory spatial tasks involving paired-associate (PA) learning were presented under conditions which either suppressed or permitted the use of imagery mediation. Differential performance of the tasks for the two presentation conditions was found to be related to the imagery concreteness of the response members of the PAs when high-imagery stimulus members were used as nonverbal cues in recall. The prediction that imagery would be used spontaneously and effectively when conditions favored its use was confirmed. The results also indicate that the mode of presentation of an instruction sentence (written vs spoken) may be an important variable in subsequent performance of a short-term memory task.

This experiment examines the hypothesis that imagery will te used spontaneously in a short-term memory task if conditions are maximized to favor its use.

Imagery, used as a mnemonic or defined in terms of stimulus attributes, has been shown to be the most effective mediator in a paired-associate (PA) learning task (Bower, 1969; Paivio, 1969, 1971). "Imageryconcreteness" or image-evoking capacity has been isolated by Paivio as the most potent stimulus attribute for facilitating PA learning. Imagery (I) and concreteness (C) are highly correlated and defined in terms of rating scale measures (Paivio, Yuille, \& Madigan, 1968). For noun pairs varying in imagery concreteness, PA learning correlated highly with the I value of the stimulus member of the pair, and to a lesser extent with the I value of the response member (Paivio, 1968). Paivio interprets this finding as evidence that high-I stimulus nouns evoke images that function as mediators in much the same way as they do in mnemonic techniques. Such techniques have repeatedly been shown to improve PA learning of concrete noun pairs compared with other learning strategies (Bower \& Winzenz, 1970). However, in the case of abstract nouns (low I), Paivio \& Foth (1970) have shown that verbal mnemonics are more effective than imagery. Moreover, Ss disregard instructional sets and readily abandon mediation strategies inappropriate for the particular type of nouns (Paivio \& Yuille, 1969).

Bower (1969) presents evidence that adult Ss have to be instructed to use interactive imagery rather than imagery per se to obtain significant improvement over verbal mnemonics in PA learning. Although Ss are known to adopt coding devices of varying complexity in PA learning, it appears that interactive imagery is not spontaneously used as a mnemonic. This may apply only to long-term memory tasks such as those used in the experiments already cited. However, Ss rarely have occasion to learn long lists of word pairs outside the experimental situation and hence their learning strategies for such tasks may not reflect those used in

The novel feature of the present experiment is that only four paired associates are used and presented on recall. A "realistic" task situation is achieved by presenting the four PAs in the form of a verbal instruction in which Ss are told to perform a nonverbal spatial task, viz, to draw or write the referent of the first noun under the referent of the second noun of the pair. The task involves cued recall in the backward (R-S) direction. It is predicted that (1) Ss will spontaneously use imagery mediation in such a task if high-I nouns are presented nonverbally as stimulus cues in recall, and (2) the initiation and effectiveness of imagery will be a function of the imagery concreteness of the response term, i.e., the first presented noun of the pair. To obtain direct evidence for the use of imagery, the technique developed by Brooks (1967) for suppressing visualization of verbal messages by varying the mode of presentation (written or spoken) was adopted. This method of selective interference has already been used by Atwood (1971) to demonstrate that mnemonic imagery actually involves visual processes.

\section{METHOD}

A short-term memory task was devised requiring actual spatial pairings of the referents of either concrete geometric shape nouns (C) or abstract number nouns (A) with concrete color nouns (C). (Such pairings are frequently encountered outside the experimental situation, e.g., in road signs, electrical connections.) Two PA lists of four shape-color (CC) and four number-color (AC) noun pairs were constructed, in which the geometric shape and number nouns were matched as closely as possible for short-term memory tasks. one occasion only for immediate free frequency, consistent with the requirement that they should also be matched for word and syllable length. The shape and number nouns were rated for concreteness (C) and imagery (I) on a 7-point scale by 32 introductory psychology students, following the procedure and instructions used by Paivio et al (1968). The nouns were interspersed in a buffer list of 20 other nouns of varying abstractness-concreteness. A period of 8 weeks separated the two ratings.

Eight color nouns-red, green, brown, yellow, white, blue, purple, and black-were used as stimulus cues and presented in nonverbal form in the recall tests. Two random pairings of the CC (shape-color) and AC (number-color) nouns were used in order to control for any possible idiosyncratic effects of specific pairs. The order of presentation of the pairs was systematically counterbalanced within each PA list. The two types of PA lists were presented in the form of instructions to carry out specific spatial tasks, e.g., Instruction Type CC: Put square under brown, oval under blue, cross under green, circle under red; Instruction Type AC: Put 3 under brown, 7 under blue, 12 under green, 11 under red. Two modes of presentation of the instructions were used to facilitate or suppress visualization, following the procedure used by Brooks (1967): listening (L) $-S$ listened to the instrustion for the length of time it took for $E$ to speak it (approximately $4 \mathrm{sec}$ ); listening and reading (LR)-S listened to the sentence spoken by $E$ and concurrently read a typewritten version of it. A constant presentation rate of $1 \mathrm{pair} / \mathrm{sec}$ was used, and to prevent $S$ from reading the instruction more than once in Condition LR, the four noun pairs were typed on separate cards and presented serially by $\mathrm{E}$. Immediately after presentation of each instruction, all of the possible eight colors were displayed in front of $S$ in the form of a horizontal array of color squares. $S$ then drew the shapes or wrote the digits under the appropriate colors, under free recall conditions and with no time limit imposed. Immediately after $\mathbf{S}$ finished the first task, the color chart was removed and the second instruction presented, following the same procedure.

In addition to the two test trials, each $\mathbf{S}$ was given a preliminary test of naming all the colors in the array (as a check for color blindness) and two practice trials of three PA pairs each, using noun pairs similar to those in the experiment. This familiarized $\mathbf{S}$ with the procedure and at the same time indicated that the second (color) 
Table 1

Mean Correct Responses and Standard Deviations Per Instruction (Out of Four) as a Function of Response Concreteness and Mode of Presentation

\begin{tabular}{lcc} 
Mode of & \multicolumn{2}{c}{ Response } \\
\cline { 2 - 3 } $\begin{array}{l}\text { Presentation } \\
\text { Listening }\end{array}$ & Concrete & Abstract \\
Mean & 3.12 & 2.75 \\
SD & 1.39 & 1.11 \\
Listening and Reading & & \\
$\quad$ Mean & 2.62 & 2.50 \\
SD & 1.28 & 1.25 \\
\hline
\end{tabular}

nouns of the pairs were to be used as stimulus cues in recall and that responses were to be made in nonverbal form. To minimize practice effects, each $\mathrm{S}$ carried out two test trials only, with one combination of each mode of presentation with each instruction type. The Ss were assigned alternately to one of two groups ( $\mathrm{N}=24$ in each group). In the first group, the $\mathrm{CC}$ pairs were presented once under Condition $\mathrm{L}$ and the $\mathrm{AC}$ pairs once under Condition LR. For the second group, the mode of presentation was reversed. In both groups, the order of presentation of the two instructions was alternated between Ss. Ss vere 48 first-year students at University College London. RESULTS

Imagery concreteness of response nouns: The mean and SD of the $C$ ratings for the shape nouns were 4.1 and 1.3 and for the number nouns were 3.1 and 1.6 , respectively. The abstract-concreteness difference for the two types of nouns was highly significant (Wilcoxon, $Z=3.75$, $\mathrm{p}<.0001)$. The mean and SD of the I ratings for shape nouns were 4.6 and 1.4 and for the number nouns were 3.6 and 1.9 , respectively. Shape nouns were rated significantly higher on I than were number nouns (Wilcoxon, $\mathrm{Z}$ $=3.35, \mathrm{p}<.0005)$. These results establish that the imagery-concreteness of the shape (C) response nouns was significantly greater than that of the number (A) response nouns.

Mean correct responses (with a maximum of four) for each type of instruction under each presentation condition are shown in Table 1 , together with standard deviations. Overall, regardless of mode of presentation, there was no significant difference in difficulty for AC and CC instruction (Wilcoxon, $\mathrm{Z}=1.24, \mathrm{p}=$ 0.22 ). Comparison of correct responses for Presentation Mode $L$ vs Presentation Mode LR showed a significant difference in the case of the $\mathrm{CC}$ instruction (median test, $\mathrm{Z}=3.0$, $\mathrm{p}<.05$ ), but no significant difference for the AC instruction (median test, $\mathrm{Z}$ $=.15, \mathrm{p}=.70)$. Comparison of correct responses under Condition $\mathrm{L}$ showed significantly better performance under CC compared with $\mathrm{AC}$ instruction $\left(x^{2}\right.$ $=5.34, \mathrm{p}<.025)$. The interaction of mode of presentation with concreteness was calculated by computing the error difference scores for each $\mathrm{S}$ for each type of instruction and comparing these difference scores between the two groups. A significant interaction was found (Mann-Whitney, $\mathrm{Z}=1.70, \mathrm{p}=.045$ ), showing that the effect of allowing Ss to visualize (under Condition $L$ ) was to produce a significant improvement in performance of the $\mathrm{CC}$ instruction relative to the $\mathrm{AC}$ instruction.

\section{DISCUSSION}

The results support the hypothesis that imagery will be used spontaneously to mediate recall of noun pairs when the task situation is realistic and conditions are appropriate for imaginal mediation, viz, if the task entails recall of verbal material in a nonverbal spatial relationship and if high-imagery stimulus members are used as cues in recall. Initiation and effectiveness of imagery, under such conditions, is shown to be related to the imagery-concreteness of the response members of the pairs.

These results accord with the dual coding theory proposed by Bower (1969) and Paivio (1969), which hypothesizes that nonverbal imagery and verbal symbolic processes are the two major components in the encoding and retrieval of verbal material and that imagery is the preferred and most effective mediator for concrete material, whereas verbal mediation is better suited to abstract material. In terms of the concrete (shape-color) noun pairs used in the present experiment, the theory predicts that recall would be expedited by the encoding of the pairs into compound images easily retrievable by the presentation of a nonverbal (high-I) stimulus cue. Such "chunking" of the noun pairs would clearly benefit recall in a short-term memory task. Suppression of imagery for such pairs would thus be expected to impair performance as indicated by the data.

In the case of abstract-concrete (number-color) noun pairs, however, the first member of the pairs would tend to be encoded in a predominantly verbal form and there would be less likelihood of encoding the pairs as compound images. This corresponds to the encoding of separate rather than related items, as discussed by Bower (1970). Presentation of a nonverbal stimulus cue, in this case, would be less advantageous for the retrieval of the abstract members of the pairs. If this analysis is correct, suppression of imagery should make little difference, as the results indicated.

A further factor which might favor recall of the concrete-concrete relative to abstract-concrete pairs was the use of backward rather than forward recall, i.e., the use of the second (or right-hand) members of the pairs as stimulus cues for recall. According to the associative directionality hypothesis proposed by Paivio (1971), visual imagery is specialized for parallel processing in the spatial sense and, to the extent that associations involve imagery, either member of the pair will be equally effective as a retrieval cue. Verbal symbolic processing, on the other hand, is specialized for sequential processing, which clearly implies directionality of associations between the pairs. To the extent that noun pairs are encoded verbally, the associations will be stronger from left to right and backward recall will be more difficult. Research findings on retrieval asymmetry related to word imagery concreteness, cited by Paivio (1971), are generally consistent with the hypothesis that the more available the imagery code, the more likely it is that associative recall will be symmetrical, i.e., independent of which member of the pairs is used as stimulus cue in recall. This hypothesis is supported by the finding in the experiment that, when imagery was permitted, there was a significantly greater number of correct pairings for the concrete-concrete pairs than for the abstract-concrete pairs.

The extent to which the variables of imagery-concreteness and mode of presentation of a verbal instruction affect the efficiency of performance of a short-term memory task, as indicated by the results of this experiment, may have more general implications. Previous research (Jones, 1966, 1968, 1970) has shown that verbal factors in instruction sentences affect performance of nonverbal tasks. The extent to which the conclusions from the present study can be generalized to other instruction sentences remains a crucial question.

\section{REFERENCES}

ATWOOD, G. An experimental study of visual imagination and memory. Cognitive Psychology, 1971, 2, 290-299.

BOWER, G. H. Mental imagery and associative learning. Fifth Annual $S$ y $\mathrm{mosium}$ in Cognition. Carnegie-Mellon University, Pittsburgh, Pa., 1969. To be published in $L$. Gregg (Ed.), Cognition in learning and memory. New York: Wiley.

BOWER, G. H. Imagery as a relational organizer in associative learning. Journal of Verbal Learning \& Verbal Behavior, $1970,9,529-533$.

BOWER, G. H., \& WINZENZ, D. Comparison of associative learning strategies. Psychonomic Science, 1970, $20,119.120$.

BROOKS, L. R. The suppression of visualization by reading. Quarterly 
Journal of Experimental Psychology, $1967,19,289-299$

JONES, $S$. The effect of a negative qualifier in an instruction. Journal of Verbal Learning \& Verbal Behavior, 1966, 5 , 495-491.

JONES, S. Instructions, self instructions and performance. Quarterly Journal of Experimental Psychology, 1968, 20, 74-78.

JONES, S. Design of instruction. Training Information Paper 1. London: Her Majesty's Stationery Office, 1970.
PAIVIO, A. A factor analytic study of word attributes and verbal learning. Journal of Verbal Learning \& Verbal Behavior, 1968, 7, 41-49.

PAIVIO, A. Mental imagery in associative learning and memory. Psychological Review, 1969, 76, 241-263.

PAIVIO, A. Imagery and verbal processes. New York: Holt, Rinehart \& Winston, 1971.

PAIVIO, A \& FOTH D. Imaginal and verbal mediators and noun concreteness in paired-associate learning: The elusive interaction. Journal of Verbal Learning \& Verbal Behavior, 1970, 9, 384-390.

PAIVIO, A., \& YUILLE, J. C. Change in associative strategies and paired-associate learning over trials as a function of word imagery and type of learning set. Journal of Experimental Psychology, 1969, 78 , 458-463.

PAIVIO, A., YUILLE, J. C., \& MADIGAN, S. Concreteness, imagery and meaningfulness values for 925 nouns. Journal of Experimental Psychology, $1968,76,1-25$.

\section{NOTES \& NEWS}

Dr. Harley A. Bernbach, formerly of Cornell University, has accepted the position of Associate Professor, Department of Psychological Sciences, Purdue Lniversity.

Dr. William H. Calhoun has completed a one-year postdoctoral fellowship under NSF's Science Faculty Fellowship Program at Indiana University, where he worked with Dr. George Heise on problems in psychopharmacology. He has now returned to the University of Tennessee where he is Professor of Psychology.

Dr. Stephen F. Davis has recently gone to Austin Peay State Lniversity, Clarksville, Tennessee, from King College. He is Assistant Professor of Psychology, teaching both undergraduate and graduate courses, and developing the animal laboratory.

Dr. Nancy Frost, has moved from the University of Washington to Princeton Lniversity, where she is Assistant Professor of Psychology.
Dr. Gilbert J. Harris has been, as of September 1, Assistant Professor of Psychology at the Herbert J. Lehman College of the City University of New York.

Dr. Kenneth R. Laughery has left the State University of New York at Buffalo to become Professor and Chairman in the Department of Psychology at the iniversity of Houston.

Dr. Geoffrey R. Loftus, previously on a postdoctoral fellowship at New York University, is currently Assistant Professor of Psychology at the Lniversity of Washington.

Dr. Lester A. Lefton, recently of the University of Rochester's Center for Visual Sciences, is now Assistant Professor of Psychology at the University of South Carolina.

Dr. Stuart J. McKelvie, who has completed his PhD at McGill University, is now Visiting Assistant
Professor of Psychology at Bishop's L'nicersity Lennoxville, Quebec.

Dr. Curtis W. McIntyre has recently completed a two-year postdoctoral fellowship at the Center for Research in Human Learning and at the Institute of Child Development, University of Minnesota. He is now Assistant Professor of Psychology at the 'niversity' of Virginia.

Dr. Lawrence C. Perlmuter, recently of Bowdoin College, is Associate Professor of Psychology, Virginia Polytechnic Institute and State Eniversity.

Dr. Robert M. Schwartz, who has recently completed his $\mathrm{PhD}$ at the University of British Columbia, is now a postdoctoral fellow (NIMH) at Stanford University, working under Dr. R. C. Atkinson.

Dr. Harry Strub is taking a sabbatical leave from the University of Winnipeg to work with David $R$. Thomas at the University of Colorado. 